\title{
Jamaican Food: History, Biology, Culture
}

B. W. Higman. 2008. University of West Indies Press, Jamaica. Pp. 580. \$70.00 (cloth). ISBN (cloth) 9789766402051.

\section{Reviewed by John Rashford ${ }^{1}$}

Reviewer Address: ${ }^{1}$ Department of Sociology and Anthropology, College of Charleston, Charleston, South Carolina 29424

Received: September $18^{\text {th }} 2009$

Published: August $3^{\text {rd }} 2010$

Barry Higman, distinguished historian and anthropologist of the Caribbean, has produced what is to date the most authoritative account of the history, biology, and culture of Jamaican food. It will be, no doubt, of great interest, not only to Jamaicans, but to scholars in diverse fields, including the ethnobiological sciences.

His interdisciplinary effort notwithstanding, Higman tells us his "approach leaves out much and that readers may wish for more on the sociology of consumption, on the role of food in society and religion, in festivals and rituals, and in politics and culture" (p. xviii). His justification for this, quite reasonable I might add, is that there "is enough in these subjects to make another book" (ibid). Higman also notes that the book could have been organized around nutrition or Jamaican "dishes" and "their combination in meals," but this would have made "difficult an analysis of origins and the story of particular ingredients, which," he tells us, was his "primary objective" (ibid). Instead, Higman chose to structure his discussion around plants and animals as sources of Jamaican food.

There are two introductory chapters and three major sections with 2 to 4 chapters each. The first chapter begins with the question "why do Jamaicans eat what they eat?" and in so doing, establishes a clear link to Raymond Sokolov's broader question posed in his book Why We Eat What We Eat: How the Encounter between the New World and the Old Changed the Way Everyone on the Planet Eats (1991). The second introductory chapter starts by pointing out that the three principle ways Jamaicans obtain food are from production based on their immediate environment, the introduction of exotic plants and animals, and trade, and it explores the choices of "what and what not to eat and drink" in Jamaica based on "systems of supply" and "taste." In this chapter Higman introduces a broad overview of the island and its history that takes us from
Volume 1:12-13

(C) 2010 Society of Ethnobiology

the original Taino to the introduction of supermarkets and fast food outlets in the 1960s.

Following the introduction, Part One focuses on the parts of plants used for food with four chapters covering roots, stems and leaves, fruits, and seeds respectively. The author's comments on his choice of this approach are worth noting. He writes: "Generally, all aspects of a particular plant have been discussed together, and the plant as a whole has been located with the part that dominates its uses" (p. xviii). This is important as it prevents what would otherwise have been a fragmented discussion of the different species of plants. Part Two deals with animals in the same way as plants and the discussion is organized around their groupings "into biological families." The first chapter of this section focuses on molluscs, crustaceans, insects, and reptiles. The remaining three chapters cover fish, birds, and mammals. Part One and Two with their focus on plants and animals comprise the most substantial parts of this book.

Part Three focuses on inorganic matter and has two short chapters. The first on salt, earth, and water and the second presents the conclusion.

In his concluding chapter Higman notes that it "may appear ironic that of the many foods consumed by Jamaicans only a small proportion are indigenous," especially when we consider that in "earlier times, the indigenous was far more important" (p.417). Higman points out that the twentieth century saw a shift in the definition of Jamaican food that was especially associated with changes in methods of processing, preparation, and cooking. Prior to the late nineteenth century, the distinct method of cooking ("founded on the abundant supply of feral animals, particularly cows and pigs" [p. 418]) was barbecue and what is popularly known in Jamaica as jerk. Today, jerk is one of Jamaica's most well-known dishes. However, many of Jamaica's most familiar foods developed from the late 
nineteenth century on, such as ackee and saltfish, rice and peas, stew peas, curry goat, patty, and bun.

Higman's conclusion also touches (for the last time) on subjects that include the relation between Jamaican food and Jamaican identity and nationalism, the Jamaica taste with its love of salt, sugar and spice, and the relevance of Marvin Harris's "cost-benefit efficiency model" for explaining (whether in Jamaica or around the world) why particular animals are eaten and others are not.

The obvious importance of food to all people and its diverse links to other areas of their lives makes it an indispensable component of any genuine attempt to understand cultural similarities and differences. Higman is well positioned to have written such an outstanding work on Jamaican culture from the vantage point of food because his mastery of the subject goes well beyond published sources. He lived in Jamaica for almost 30 years and taught history at the University of the West Indies where he was also Chair of the History Department. Although Jamaican Food was written at the Australian National University's History Program (of the Research School of Social Sciences), Higman began systematic research for the book in the middle of the 1980s. Barry Higman is a delightful colleague and friend and I remember well our enjoyable and informative explorations of the Jamaican landscape.

The book is well illustrated with many black-andwhite drawings done by William Murray, several useful maps, and 40 plates of beautiful late eighteenth-century watercolor paintings by Reverend John Lindsay depicting many of the edible plants and animals of Jamaica. Jamaican Food is rich in citations with an excellent bibliography and a thorough index. The index, in particular, will make this book a valuable resource for all who are interested in Jamaican foods and related subjects, and in the relationship between food and the making of our present world system. 